\title{
Teori ya da Realite: Hâkim Terapi Kuram ve Uygulamaları Karşısında Konumlanış ve Arayışlar*
}

\author{
Latif Karagöz**
}

Öz: Bu çalışmada bazı psikoterapistlerin Türkiye'de psikoloji biliminin ve terapi hizmetlerinin mevcut durumunu nasıl değerlendirdikleri, terapi uygulamalarındaki kuramsal ve yöntemsel tercihlerinin neler olduğu, hâkim kuram yöntemler karşısında alternatif arayışlarının olup olmadığı araştırılmıştır. Bunun yanında terapistlerin sıklıkla karşılaştıkları aile problemlerini ve ailedeki değişim ve dönüşümü nasıl değerlendirdikleri de incelenmiştir. Bu amaçla İstanbul'da görev yapan 10 terapi uzmanı ile derinlemesine görüşmeler yapılmıştır. Görüşmelerin sonunda, katılımcıların özellikle bazı noktalarda kendilerine gelen aile meselelerini ve toplumsal olarak ailedeki değişimi değerlendirirken geleneksel/kültürel referanslarla hareket ettikleri görülmüştür. Buna mukabil, katılımcıların büyük çoğunluğunun bu meselelere ve karşılaştıkları diğer problemlere çözüm üretirken hâkim/Batılı kuram ve yöntemleri benimsedikleri görülmüştür. Terapi sürecinde ortaya çıkan eksikliklerin ise eklektik bir yöntem tercih edilerek ve/veya terapistlerin kişisel gayret ve becerileri ile giderilebileceği düşüncesinde yoğunlaşmışlardır. Bu eksikliklerin giderilmesi için alternatif yaklaşımlar geliştirilmesi gerektiğini vurgulayan az sayıdaki katılımcı ise (2 kişi) muhtelif nedenlerden dolayı bunu hayata geçiremediklerini belirtmişlerdir. Buradan hareketle psikoterapide hem kuramsal hem de uygulamalı olarak Batılı bilgiye bağlılığın, insanı ve toplumu bu bilgi anlayışı ve insan tasavvuru üzerinden anlamlandırma durumunun devam ettiği söylenebilir.

Anahtar Kelimeler: Psikoloji, Psikoterapi, Türkiye, Terapi Kuramları, Terapi Yöntemleri.

\begin{abstract}
In this study, it is investigated how certain psychotherapists evaluate the current state of psychology as a science and psychotehrapy services in Turkey, what the theoritical and methodological preferences on theraphy practices are, and whether these experts these experts search for alternatives against dominant theories and methods. It is also investigated how therapists evaluate the change and transformation in family, and the family problems they face. For this purpose, in-depth interviews were conducted with 10 therapists practising in Istanbul. It is determined that participants behave with traditional/cultural references while they evaluate the transformation in family and especially family problems. On the contrary, it is concluded that the majority of participants adopt dominant/Western theories and methods. They emphasize that the various deficiencies emerging in the process of theraphy can be eliminated by choosing an eclectic method and/or individiual efforts and skills of the therapist. A small number of participants emphasising the need for alternative approaches stated that they could not apply them because of various reasons Thus it can be said that in psychotherapy, the state of both theoretical and practical dependence on Western knowledge, and the interpretation of individiuals and society via this understanding, and conception, is ongoing.
\end{abstract}

Keywords: Psychology, Psychoteraphy, Turkey, Theories of Theraphy, Methods of Theraphy.

* Bu makale ILKE Ilim Kültür Eğitim Derneği için hazırlanan bir araştırmanın gözden geçirilmesi ile oluşturulmuştur. Araştırma sürecindeki tüm katkılarından dolayı ILKE'ye teşekkür ederim.

** Arş. Gör., Fatih Sultan Mehmet Vakıf Üniversitesi Psikoloji Bölümü

Iletişim: Ikaragoz@fsm.edu.tr, Fatih Sultan Mehmet Vakıf Üniversitesi Edebiyat Fakültesi, 34083, Fatih, İstanbul.

Atıf@: Karagöz, L. (2012). Teori ya da realite: Hâkim terapi kuram ve uygulamaları karşııında konumlanış ve arayışlar. Insan ve Toplum, 2 (3), 93-117. 


\section{Giriş}

Psikoloji bilimi, insanı ve toplumu ele alış şekliyle modern bilimsel söylem içerisinde -objektif, deneye dayalı, evrensel geçerliliği olan - bilgilerini üretmektedir. Dolayısıyla insana ve topluma dair ortaya koyduğu pratikler de bu çerçevede olmaktadır. 1960 sonrası süreçte sosyal bilimlerde yaşanan paradigmatik kriz, psikoloji biliminin temel faraziyelerine ciddi eleştiriler yöneltilmesini ve kültürü merkeze alan çalışmaların, yayınların çok daha görünür olmasını sağlamıştır (Jahoda ve Krever, 1996; Kim, Yang ve Hwang, 2006). Kültürlerarası psikoloji, kültürel psikoloji, yerel(indigenous) psikoloji gibi ekoller, kültürü psikolojik çalışmaların merkezine yerleştirmeye gayret etseler de Batı kökenli ana akım psikoloji kuram ve uygulamalarının bazı önemli istisnalara rağmen büyük oranda psikolojideki hâkimiyetini sürdürdüğü (Kağıtçıbaşı, 2010) görülmektedir.

Bu durum, büyük oranda Türk psikoloji camiası için de geçerlidir. Gerek Türkiye'deki psikoloji tarihi yazımına gerekse tarihsel süreçteki kurumsallaşmalara, uygulamalara bakıldığında benzer bir durumun söz konusu olduğu söylenebilir. Örneğin, Türkiye'de psikoloji biliminin başlangıcı olarak Dr. George Anschütz'ün 1915'te İstanbul'a gelişinin kabul edilmesi, Batur'a (2003) göre Türkiye'de psikoloji dünyasına hâkim olan anlayışın bir neticesidir. Çünkü bu yaklaşım psikolojiyi yalnızca deneysel psikolojiye indirgemekte, psikolojideki diğer anlama biçimlerini ise görmezden gelmektedir.

Kuş (2007), sosyal bilimlerdeki paradigmatik dönüşümün psikoloji alanındaki yansımalarını incelediği çalışmasında, sosyal bilimlerin tüm disiplinleri içinde pozitivist paradigmaya alternatif yaklaşımlar ortaya konulduğunu; ancak bu köklü dönüşüm sürecinden en az psikoloji biliminin etkilendiğini söylemektedir. Türkiye'de psikologların -pozitivist yaklaşımların dışında yer alan bir teknik olarak-nitel teknikleri kullanıp kullanmadıklarını/ne ölçüde kullandıklarını araştırdığı bu çalışmasında, araştırmaya katılan psikologlar hem nitel araştırma bulgularını yayınlatacak dergileri bulmakta hem de akademik destek bulmakta zorluk yaşadıklarını ifade etmişlerdir. Kuş'un bu bulguları, onun psikolojideki pozitivist anlayışın halen daha gücünü devam ettirdiğine dair tespitlerini destekler mahiyettedir.

Misra ve Gergen'e (1993) göre psikoloji, öncelikli olarak Avrupa-Amerikan kültürünün bir ürünüdür. Ancak bilim olmanın gereği olarak sunulan, değerden/kültürden bağımsız olma fikri ve ekonomik emperyalizm vasıtasıyla bu Batılı yerel psikoloji, Batılı olmayan toplumlara taşınmaktadır. Kağıtçıbaşı (2010) da psikolojinin ithal edilmiş bir bilim dalı olması hasebiyle, Batı dışı toplumlarda önemli sosyal olaylara yabancı kaldığını, dolayısıyla bu toplumlarda bilgi üretmek yerine Batılı kuram anlama biçimlerini transfer etmekle iktifa ettiğini vurgulamıştır. Bu yönüyle psikoloji biliminin, Batı dışı toplumlarda Batılı insan tasavvurunun, bilgi anlayışının, anlama biçimlerinin insana ve topluma ulaştırılmasında ve bu şekilde buradaki insanın ve toplumun dönüştürülmesinde önemli bir işlev gördüğü söylenebilir. Bu durum, Arkonaç (2010) tarafından, 
Batılı epistemolojinin özne/kimlik/fail ve gerçeklik bilgisinin kendi elitleri eliyle bu coğrafyaya taşınması, dolayısıyla "psişenin sömürgeleştirilmesi" şeklinde yorumlanmıştır.

Psikolojinin alt alanlarının her biri incelendiğinde yukarıdaki tespitlerin yansımaları net bir biçimde görülecektir. Gelişim psikolojisi alanında yapılan çalışmalar, psikolojinin bu yönünü en iyi yansıtan alanlarından biri olması nedeniyle önem arz etmektedir. Zira gelişim psikolojisi, insanın doğum öncesi hayatından itibaren çocukluğuna, okul, evlilik ve iş hayatına, yaşlılığına dair çok geniş bir yelpazede bilimsel bilgi üretmektedir. Sahip olduğu Batılı "evrensel" bilgi anlayışı ile insan ve toplum hayatına -hem teorik hem de uygulamalı olarak- önemli ölçüde müdahil olmaktadır. Kağıtçıbaşı (2010), mevcut gelişim psikolojisi ders kitaplarının büyük çoğunluğunda kültürel farklılıkların vurgulanmayıp bu farklııkların konu dışı ele alındığını belirtmiştir. Son zamanlarda kültürü merkeze alan bazı kitapların ortaya çıkmasına rağmen kültürün çoğunlukla çalışmaların merkezinden uzak, ikincil olarak ele alındığını vurgulamıştır. Robinson (2001) da son dönemde kültür merkezli çalışmalar yürüten psikologların çalışmalarında artış olsa da günümüz gelişim psikolojisinin hâkim bilgilerinin Avrupalı-Amerikan psikologlar tarafından, kendi kültürel deneyimleri neticesinde üretildiğini belirtmiştir.

Ergenlik üzerine yapılan çalışmalar ve uygulamalar, gelişim psikolojisinin bu yönünü anlamak için önemlidir. Yaklaşık 12-22 yaş arası uzun bir süreci kapsayan bu döneme ait çok fazla sayıda akademik ve popüler yayın mevcuttur. Bu bağlamda gelişim psikolojisi kitapları, bu alandaki makaleler vb çalışmalar incelendiğinde, ergenlik deyince çoğunlukla hüzün, güvensizlik, karamsarlık beden ve ruhun dengesizliğinden dolayı ortaya çıkan kaos, suçluluk, utanç, karşı cinse ilgi duyma gibi temel bazı özelliklerle karşılaşımaktadır. Türkiye'de gelişim psikolojisi alanında yaptığı çalışmalarla tanınan bazı akademisyenlerin ergenliğe dair bazı yorumları da söz konusu tespitleri güçlendirmektedir.

Parman (2010, s. 22), ergenlik hakkında, "Insan yaşamının hiçbir dönemi için bu denli birbirine zıt ve karmaşık tanımlar yapılmaz." tespitinde bulunurken, Kulaksızoğlu'na (2009, s. 52) göre, "Çocukluk ve ergenlik yıllarındaki kız erkek beraberliğinde geçirilen gelişim aşaması, tamamen o çağa has, yaşlara bağlı ve bütün toplumlarda görülen bir özelliktir". Bu çerçevede Saynur Canat'ın ergenliğe yönelik yorumları da oldukça manidardır:

"Ergenlik; anne babadan duygusal olarak ayrılma, onların sevgi ve desteğine daha az ihtiyaç duyma, gencin daha bağımsız ve kendine yeter duruma gelmek için hazırlık dönemidir. Bu süreçte, aile içi ilişkiler azalırken aile dışındaki arkadaş ve diğer çevrelerle olan ilişkiler de artmaya başlar. Ailenin gencin duygusal olarak kendine yeter hale gelebilmesi ve 'bireyleşebilmesi' için uygun davranışlar içinde olması beklenir." (akt., Kulaksızoğlu, 2009, s. 121)

Ergenlikle ilgili bu tespitlerde, ergenlik dönemi olarak tanımlanan ve yaklaşık olarak 12-22 ya da 12-18 yaş dönemlerindeki insana dair tespitlerin, oldukça modern, seküler, 
kısmen de ergenleri neredeyse psikopatolojiye yatkın olacak şekilde tanımlamış oldukları söylenebilir. Dolayısıyla kişilik oluşumundaki en önemli evreler denilebilecek bir dönemdeki insanı tasvir ederken kullanılan bu akademik dil, aynı zamanda bu düşünce yapısının insana ve gence yönelik tasavvurunu da göstermektedir. Akademik eğitimleri boyunca bu bilgilerle yetiştirilen psikolog, psikolojik danışman ve öğretmenlerin meslek hayatlarında danışanlarıyla ve öğrencileriyle kurdukları mesleki ilişkinin çerçevesini bu bilgilerin oluşturduğu düşünüldüğünde, meselenin pratiğe bakan tarafının oldukça manidar olduğu söylenebilir. Her ne kadar anne babadan bağımsız hale gelme, referans grubunun arkadaşlara kayması gibi ergen özelliklerinin bütün toplumlarda görülmediğine dair literatürde bazı çalışmalar var olsa da (akt., Kağıtçıbaşı, 2010) Türkiye'de psikoloji alanında bu döneme dair yapılan çalışma ve uygulamaların büyük çoğunluğu için böyle bir farkındalığın söz konusu olmadığını söylemek mümkündür.

Ergenlikle birlikte çocuk yetiştirme tutumları konusu da özellikle gelişim psikolojisi kitaplarında ve diğer akademik yayınlarda önemli bir yer tutmaktadır. Hemen hemen bütün gelişim psikolojisi kitaplarında; demokratik tutum, otoriter tutum, izin verici hoşgörülü tutum, izin verici ihmalkâr tutum ve aşırı kollayıcı tutum olmak üzere 5 çocuk yetiştirme tutumundan bahsedilmektedir. Bunlar arasında en uygun yaklaşım olarak demokratik tutum gösterilmektedir. Şendil ve Kaya Balkan'a (2005, s. 80) göre, "Bu yaklaşıma mensup aileler çocuklarının birey oluşlarının farkındadırlar, onların kendilerini gerçekleştirmelerine izin verirler, onlara aile içinde eşit haklar tanırlar, düşüncelerini açıkça anlatmalarını desteklerler ve böylece onların bağımsız kişilik geliştirmelerine yardımcı olurlar." Kulaksızoğlu (2009, s. 119) da bu yaklaşıma sahip bir aileyi şu şekilde tarif etmektedir:

"Çocuğa, aile içinde eşit haklar tanınmıştır. Fikirlerini açıkça ifade etmesi desteklenir ve bu konuda cesaretlendirilir. Eşitlikçi tutum gösteren anne baba, çocuklarına karşı daha arkadaşça yaklaşır, onlarla birçok şeyi paylaşırlar, onlara değer verirler ve bunu ona hissettirirler. Anne babalar, katı kurallar koymak yerine esnek davranmasını da bilirler."

İdeal çocuk yetiştirme tutumu olarak sunulan demokratik aile tutumu derinlemesine tahlil edildiğinde, bu yaklaşımın anne babaların çocukları ile olan ilişkilerini kaygan hatta belirsiz bir zeminde tanımladığı söylenebilir. Dolayısıyla teorik olarak aile içindeki rollerin eşitlik üzerinden tanımlanması, anne babaya arkadaşlık üzerinden bir konum verilmesi, ana baba disiplini yerine esnekliği ön plana çıkarması ve "kendini gerçekleştirme" adı altında değer yargılarından kopuk bir birey vurgusunun, toplumsal pratikler üzerinde menfi yönde ne tür tesirlerinin olduğunun sorgulanması gerekmektedir. Zira bu şekilde "ideal" olarak sunulan bir yaklaşım, ebeveyn-çocuk ilişkisinin mahiyetini tespit ve tahlil ederken kültürün rolünü yine görmezden gelmektedir. Ancak Sümer'in (2005) de belirttiği gibi pratikte Türkiye'de çocuk yetiştirme tutumları, kültüre ve sosyoekonomik düzeye göre farklılıklar göstermektedir. Dolayısıyla bu durum, ortay 
konulan kuramsal bilgilerin toplumun anlam dünyası ve pratikleri çerçevesinde oluşturulmasının gerekliliğini de göstermektedir.

Psikolojinin ürettiği, yukarıda özel olarak gelişim psikolojisi çerçevesinde ele alınan, teorik/kuramsal bilgilerin pratiğe ne tür yansımalarının olduğunu görmek, Türkiye'de psikoloji biliminin mevcut durumuna dair daha nitelikli ve bütüncül bir değerlendirme yapabilme imkânı sağlayacaktır. Bu nedenle Psikoloji biliminin pratiğe yansıyan tarafının en iyi görülebileceği zemin olması hasebiyle bu kuramsal bilgilerle donanan terapi uygulayıcılarının ve uygulamalarının Türkiye'deki mevcut durumunu incelemek önem arz etmektedir. Fişek (1996), kuramsal ve ideolojik kökenleri Batı Avrupa ve Kuzey Amerika olan psikoterapilerin diğer kültürlerde nasıl ele alındığına literatürde çok az değinildiğinden söz etmektedir.

Bu bağlamda, bu çalışmada psikoterapi hizmeti veren psikolog, psikolojik danışman ve psikiyatristlerin Türkiye'de psikoloji biliminin ve psikoterapi hizmetlerinin/uygulamalarının mevcut durumunu nasıl değerlendirdikleri, hâkim Batılı kuram ve uygulamaları nasıl anlamlandırdıkları ve bunlara alternatif yaklaşımlar geliştirme noktasında herhangi bir arayışlarının olup olmadığı tespit edilmek istenmiştir. Bununla birlikte önemli toplumsal meselelerden biri olan aile problemlerini, ailedeki değişim ve dönüşümü değerlendirirken hangi referanslarla hareket ettiklerini tespit etmek de istenmiştir. Buradaki amaç, terapistlerin toplumsal bir meseleyi ele alırkenki bakış açıları ile bu meselelere çözüm üretirken benimsedikleri kuram ve uygulamalar arasında bir bütünlük/uyum olup olmadığını tespit etmektir.

\section{Yöntem}

Bu araştırmada, nitel araştırma tekniklerinden biri olan derinlemesine görüşme tekniği kullanılmıştır. Derinlemesine görüşme tekniği, "açık uçlu soruların sorulması, dinlenmesi, cevapların kaydedilmesi ve ilişkili ilave sorularla araştırma konusunun detaylı bir şekilde incelenmesini mümkün kılar." (Kümbetoğlu, 2008, s. 71). Bu yönüyle derinlemesine görüşme tekniği, Kümbetoğlu'nun ifade ettiği gibi sosyal dünyadaki olguların görünür taraflarının ötesine geçerek bu olguların özüne inmeyi, onları daha derinden, ayrıntılı ve bütüncül bir şekilde incelemeyi sağlamaktadır.

Araştırma sürecinde derinlemesine görüşmelerde kullanılmak üzere yarı yapılandırılmış görüşme formu hazırlanmıştır. Yarı yapılandırılmış görüşmeler araştırmacıya daha önceden belirlenmiş temalar çerçevesinde görüşmeleri sürdürme imkânı sağlamaktadır. Bununla birlikte görüşme esnasında ortaya çıkabilecek yeni temalar ve durumlar hakkında da sorular sorabilme, görüşmeyi genişletebilme esnekliği sağlamaktadır.

Bu amaçla, öncelikle pilot çalışma niteliğinde bir elektronik soru formu hazırlanmıştır. Soru formu, uzmanların aile içi ilişkiler bağlamında ne tür problemlerle karşılaştıkları, 
bu problemlerde ortak özellikler olup olmadığı, son yıllarda terapi hizmetlerine yönelik yoğun talebin nedenlerinin neler olabileceği, Türkiye'de psikoloji biliminin ve terapi uygulamalarının mevcut durumunun nasıl değerlendirdikleri, ne tür eğitimler aldıkları ve neden bu eğitimleri tercih ettikleri, mesleki uygulamalarında hangi kuram ve terapi yöntemlerinin daha açıklayıcı ve çözüm üretici olduğu, bu kuram ve tekniklerin eksik kalan yönlerinin olup olmadığına dair toplam 14 soruyu içermiştir. bununla birlikte, uzmanların sıklıkla karşılaştıklarını düşündüğümüz üç vaka örneği hazırlanarak uzmanların bu vakalara çözüm üretirken nasıl bir yöntem izledikleri sorgulanmıştır.

$\mathrm{Bu}$ elektronik soru formu, alanda hizmet veren bazı terapi uzmanları vasıtasıyla e-posta yoluyla yaklaşık 30 psikoterapi uzmanına ulaştırılmıştır. E-posta gönderilen kişilerden 8 tanesi araştırma formunu doldurup geri bildirimde bulunmuştur. Elde edilen geri bildirimler neticesinde soru formunda bazı düzenlemeler yapılmıştır. Buna göre 3 vaka örneği ve bazı sorular formdan çıkarılarak toplam 11 sorudan oluşan yeni bir soru formu oluşturulmuştur. Bu yeni soru formu da yine bazı uzmanlar vasıtasıyla yaklaşık 30 terapi uzmanına e-posta yoluyla gönderilmiş, 5 kişi formu doldurup geri bildirimde bulunmuştur.

Formlardan elde dilen geri bildirimler ve değerlendirmelerden istifade edilerek, yarı yapılandırılmış görüşmelerde kullanılacak olan sorular oluşturulmuştur. Yarı yapılandırılmış görüşme formu genel olarak karşılaşılan aile problemleri ve bu problemlerdeki ortak özellikler, Türkiye'de psikoloji biliminin, terapi ve danışmanlık hizmetlerinin durumu, benimsenen kuram ve yöntemlerin neler olduğu, bu kuram ve tekniklerin gelen problemleri açıklamada eksik kalan yönlerinin olup olmadığı, eksik görülen kısımların nasıl giderildiği, bu yönde kişisel ya da kurumsal bir çabanın olup olmadığı gibi soruları içermektedir.

Araştırmada, İstanbul'da mesleklerini icra eden ve özellikle aile, çocuk ya da ergenlerle çalışan 10 psikoterapi uzmanıyla görüşmeler yapılmıştır. Bu uzmanların üçü psikiyatrist, dördü psikolog ve diğer dördü de psikolojik danışman olarak görev yapmaktadır. Görüşme yapılan kişilerin seçiminde, nitel araştırmalarda sıklıkla kullanılan "kartopu örneklem" oluşturma biçimi kullanılmıştır. Böylece kaynak kişilerden görüşülecek diğer kişilere ulaşılmıştır. Kartopu örneklemde, sadece belirli grup ya da kişilere ulaşıma riski mevcuttur (Kümbetoğlu, 2008, s. 99). Bu sebeple araştırmada bu risk iki kaynak kişi belirlenerek aşılmaya çalışılmıştır. Kartopu örnekleme ilave olarak bu çalışmada aşırı veya aykırı durumların normal durumlara göre daha zengin veri ortaya koyabileceği, bu şekilde de araştırma probleminin derinlemesine ve çok boyutlu bir biçimde anlaşılmasının sağlanacağı (Yıldıım ve Şimşek, 2000) düşünülerek aşırı veya aykırı durum örneklemesi de kullanılmıştır. Böylece bilgi bakımından zengin durumların derinlemesine incelenmesi mümkün hale gelmiştir. Bu araştırmada, görüşme yapılan 10 kişiyi seçerken "kaynak kişilerden" araştırmacıyı, çalışmalarında daha yerel/kültür odaklı bir söylem benimseyen terapi uzmanlarına yönlendirmeleri istenmiştir. Bu terapi uzman- 
ları, bu özellikleriyle, evrenin diğer üyelerine nazaran yerel/kültürel bilgilerin üretilmesi, mevcut terapi yaklaşımlarına daha eleştirel bakılması ve alternatif yaklaşımlar geliştirilmesi anlamında daha ön planda olan kişiler olarak düşünülmüşlerdir.

Görüşmeler, önceden randevu alınarak belirlenen gün ve saatlerde, uzmanların çalıştıkları kurumlara gidilerek gerçekleştirilmiştir. Uzmanlarla yapılan görüşmelerin ses kayıtları alınmıştır ve bu kayıtlar deşifre edilmiştir. Bu metinler, araştırmacı tarafından birkaç defa okunarak nitel veri analizi yöntemlerinden biri olan "sistematik analiz" ile analiz edilmiştir. Sistematik analizde, "bazı nedensel ve açıklayıcı sonuçlara ulaşmak amacı ile verilerin betimsel olarak sunulmasına ilave olarak, verilerde yer alan bazı kavram ve temaların belirlenmesinden sonra bunlar arasındaki ilişkiyi tanımlamak esastır" (Kümbetoğlu, 2008, s. 154). Bu çalışmada da elde edilen verilerden hareketle belli ortak temalar oluşturulmuş; katılımcıların yanıtları, bu temalar altında tasnif edilmiştir. Toplam 13 elektronik soru formundan elde edilen veriler de belli kategoriler altında tasnif edilmiştir. Daha sonra hem görüşmelerden hem de elektronik soru formlarından elde edilen sonuçlar, bütünlük içerisinde analiz edilmiştir.

\section{Bulgular}

Bu bölümde araştırmaya katılan terapi uzmanlarının Türkiye'de psikoloji biliminin ve terapi hizmetlerinin durumuna, benimsemiş oldukları terapi kuram ve yaklaşımlarının neler olduğuna, kendilerine gelen-sıklıkla karşılaştıkları- aile problemlerinin mahiyetine ve ailedeki değişim ve dönüşüme dair değerlendirmelerine yer verilmiştir. Bununla birlikte elektronik soru formlarından elde edilen veriler de bu değerlendirmlerle birlikte ele alınmıştır. Yapılan doğrudan alıntılarda katılımcıların isimleri kodlanmış ve gerçek isimleri gizli tutulmuştur. İsim kodlarıyla beraber yalnızca katılımcıların mesleki kimlikleri açık bir şekilde yazılmıştır.

\section{Türkiye'de Psikolojinin ve Terapi Hizmetlerinin Durumunun Değerlendirilmesi}

Araştırmada, katılımcılardan her yönüyle giderek daha fazla talep edilen psikolojinin ve bu bilimin uygulamadaki en önemli ayağını temsil eden terapi hizmetlerinin Türkiye'deki durumunu değerlendirmeleri istenmiştir. Katılımcıların bu değerlendirmeleri, terapi hizmeti veren uzmanların ve kurumların yetkinlikleri, akademik eğitimin ve yayınların durumu olmak üzere, iki ana başlık altında incelenmiştir.

Katılımcıların tamamı, alanda terapi hizmeti veren kişilerin büyük çoğunluğunun gerekli yetkinliğe sahip olmadıklarını belirtmişlerdir. Bunda hem özel terapi eğitimi veren kurumlardaki hem de üniversitelerdeki eğitimin niteliğindeki problemlerin etkili olduğunu vurgulamışlardır. Bununla birlikte katılımcıların çoğu, ortak bir şekilde, psikoterapi alanında "çok paranın dönmesi" nedeniyle, bazı sertifikaları edinip kendisine terapist diyen; fakat hiçbir yetkinliği olmayan kişilerin bulunduğunu belirtmişlerdir: 
"İ̧̧te gidip bir sertifika programına katılıyorlar, işte bir NLP alıyorlar vesaire vesaire onu çok böyle süslü can conlu şeylerle sunup insanları kandırıyorlar. Insanlarımız da ne yazık ki bu konuda yetkin şeylere bakmıyor. Sertifikasyonu var mı, hani o konuda esasında toplum bu konuda bilinçli değil. Eğer çok güzel bir görüntü varsa hemen ona kanıp nereden mezun, yetkinliği var mı diye bakmıyor. Hani bu da çok içler acısı ve o grup da esasen psikologların adını kötü çıkaran bir grup diye düşünüyorum ben"..[N.A., Psikolog]

Katılımcıların tamamına göre bu durumu ortaya çıkaran en önemli etken, ruh sağlığı alanında bir yasal düzenlemenin olmayışıdır. Yasal düzenlemedeki bu eksikliğin de bu alanda hizmet veren kişi ve kurumların denetlenmesini, kontrol edilmesini engellediği yönünde ortak bir görüş mevcuttur. Bazı katılımcıların ifadeleriyle ruh sağlığı yasası ile "terapinin tanımının ve çerçevesinin çizilmesi, bu mesleği icra etmek için gereken yetkinliklerin belirlenmesi"[F.Y., Psikiyatrist] ve "psikoterapistin Sağlık Bakanlığı'nda bir karşıığının olması, tanınması, sisteme dahil edilmesi, terapi hizmetinin sigorta kapsamına alınması" [M.D., Psikolog] gibi düzenlemelerin yapılması gerekmektedir.

Katılımcılara göre yasal düzenlemenin olmayışı terapi eğitimi veren kurumların da belirli standartlardan yoksun bir şekilde hizmet vermelerine neden olmaktadır. Aynı zamanda "hep dışarıdan alınması gereken" [Y.A., Psikolog] bu eğitimlerin yoğun bir şekilde talep edilmesi, çoğu katılımcıya göre alanın maddi çıkar sağlamak için kullanılmasına neden olmaktadır. Bu da "bilimsel hiçbir geçerliliği olmayan"[F.Y. psikiyatrist] standardizasyonu olmayan terapi yöntemlerinin, ekollerinin kullanılmasına neden olmaktadır. Dolayısıyla bu çerçevede değerlendirildiğinde, "insanlara sunulan terapi hizmeti yaygınlaşsa da kalitenin aynı oranda artış göstermediği" [H.A.G., P. Danışman] tespitinde bulunulmaktadır.

Hem görüşme yapılan hem de soru formlarını yanıtlayan bazı katılımcıların vurguladığı başka bir nokta da Türkiye'de psikoloji alanında bu kültüre ait, geçirilen değişim dönüşümlere rağmen bu toplumun değişmeyen bazı özelliklerine özgü bir yaklaşımın geliştirilmesindeki eksikliktir. Ancak, bu ihtiyacın son zamanlarda sıkça gündeme getirilmesi, bir katılımcıya göre başka bir problemi de ortaya çıkarmıştır:

"Şimdi bu alandaki ihtiyaç bir şekilde gözüküyor. Bu ihtiyacın farkına varan bazı uyanık tipler bu medeniyete uygun psikoloji, Mevlana'nın dediği psikoloji falan filan diye inanılmaz şaklabanlıklar yapıyorlar ve bu bana açıkça ihanet gibi geliyor... Gerçekten istismar ediyor bir grup insan ve feci istismar ediyor ve bu istismarın en çok yapıldığı yerlerden bir tanesi, şu anda psikoloji."[M.D., Psikolog].

Alanın bu şekilde "istismar edilmesi", aslında bir intiyaç olarak tespit edilen kültür odaklı yaklaşımların geliştirilmesinin, bu alanda nitelikli çalışmalar yapılmasının da önünü tıkadığı belirtilmiştir. Bunun dışında, alanda hizmet veren psikiyatrist, psikolog ve psikolojik danışmanlar arasındaki irtibatsızlığın, hatta bazı katılımcıların vurguladığı gibi "rekabet ve çekişmenin" de özellikle danışanların nitelikli hizmet alması 
noktasında önemli aksaklıklara sebebiyet verdiği ifade edilmiştir. Bununla birlikte bazı katılımcılar terapi hizmeti veren kişi ve kurumlarda gördükleri bu eksiklikler nedeniyle, bu hizmetleri talep eden danışanların terapiden yeterince istifade edemediklerini belirtmişlerdir. Hatta bir katılımcı, "Türkiye'de danışmalar hangi terapötik yaklaşıma yakın durursa dursunlar, danışanların \%70-80'inin en fazla 4 seans sonra terapiye gelmeyi bıraktıklarını" ve "terapistlerin çoğunun danışanın pobleminini belirledikten sonraki aşamada ne yapacakları konusunda kafalarının karışık olduğunu" [H.A.G., P. Danışman] iddia etmiştir.

Görüşme yapılan katılımcıların çoğu, psikoloji alanında lisans ve lisansüstü düzeydeki akademik eğitimin yetersiz olduğunu vurgulamışlardır. Psikoloji bölümlerine çok yoğun bir talebin olduğu, çok fazla yeni psikoloji bölümünün açıldığı gerçeğine rağmen lisans eğitimlerinin çok fazla teorik, kuramsal düzeyde kalması, çok kısıtlı şekilde uygulama içermesi katılımcılar tarafından en önemli eksiklikler olarak görülmüştür. Dolayısıyla bu şekilde, "üniversitelerde yapılandırılmış terapi eğitiminin olmayışı" [K.S., Psikiyatrist] "lisanstan mezun olurken terapist kimliğinden çok uzak bir şekilde mezun olunması" [Y.A., Psikolog] gibi bir problemi ortaya çıkmaktadır. Başka bir katılımcı, çok fazla yeni psikoloji bölümünün açılmasını özellikle özel üniversiteler için psikoloji bölümünün önemli ölçüde para getirisi sağlamasına dayandırmıştır.

Katılımcılar, lisansüstü eğitimin ihtiyacı karşılayacak düzeyde olmadığı noktasında ortak görüş bildirmişlerdir. Bu durumu ortaya çıkaran en önemli etkenin de lisansüstü eğitim verecek öğretim üyesi eksikliği olduğu belirtilmiştir. Bununla birlikte bazı katılımcılar, lisansüstü eğitimin, özellikle terapi becerisi anlamında öğrencileri ancak sınırlı bir yere kadar getirebildiği için yeterli altyapıyı vermediğini belirtmişlerdir. Bu durumun da kişileri yetersizlik duygusuna sevk ettiği ve "dışarıdan" terapi eğitimi almaya mecbur bıraktığı vurgulanmıştır. Bu tespitler, katılımcıların önceki kısımlarda terapi eğitimi veren kurumlara ve burada verilen eğitimlere yönelik değerlendirmeleri ile birlikte ele alındığında, genel olarak üniversitelerde ve özel merkezlerde gerekli yetkinliğe sahip terapistlerin yetiştirilmesi noktasında ciddi bir problemin var olduğunu göstermektedir.

Katılımcılar arasında ve soru formlarında, Türkiye'de psikoloji alanındaki akademik yayınların mevcut durumuna dair iki farklı görüş ortaya çıkmıştır. Bazı katılımcılar Türkiye'de psikoloji literatüründeki akademik yayınların gerekli niteliğe sahip olmadıklarını belirtmişlerdir. Bu düşüncelerini de "yapılan yayınların birbirlerini tekrarlaması" ve "kültür odaklı çalışmaların olmayışı" üzerinden açıklamışlardır. Bu görüşe sahip olanlar, psikolojideki akademik yayınların -özellikle kitapların- genelde "tercüme üzerinden gittiğini" savunmuşlardır. Diğer bazı katılımcılar ise psikolojideki akademik yayınların şu an yeterli düzeyde olmasa da geçmişe nazaran çok daha iyi bir seviyede olduğunu belirtmişlerdir. Bu tespitlerini, daha fazla akademik yayın yapılması ve uluslararası dergilerde Türkiye'den daha fazla akademisyenin yayınlarının yer alması ile desteklemişlerdir. 


\section{Uzmanların Benimsemiş Oldukları Terapi Kuram ve Teknikleri}

Görüşmeler boyunca katılımcıların terapi hizmeti verirken hangi kuram ve terapi tekniklerini benimsediklerine, dolayısıyla kendilerini nasıl ve nerede konumlandırdıklarına dair sorular sorulmuştur. Katılımcıların çoğu, bireysel terapi hizmeti sunarken bilişsel davranışçı yaklaşımları benimsediklerini vurgulamışlardır. Bunda bilişsel davranışçı ekolün, "her zaman daha tutarlı olması" (F.Y. Psikiyatrist] ve "insanların günlük hayatta karşılaştıkları patolojiye yakın problemlere daha uygun olması"nın [M.D., Psikolog] etkili olduğunu belirtmişlerdir. Bunun dışında bazı katılımcılar da psikoanalitik, varoluşçu, hümanistik, gestalt ve benönötesi (transpersonel) terapi yaklaşımlarını benimsediklerini söylemişlerdir. Ancak, Türkiye'de varoluşçu, hümanistik ve gestalt terapi yaklaşımlarının detaylı eğitimini verecek kurumlar olmadığı için katılımcılar, bu yaklaşımları sadece problemleri değerlendirme aşamasında kullandıklarını belirtmişlerdir. Bunların dışında bir katılımcı, biyolojik psikiyatri yaklaşımını, bir diğeri ise "kendi tarih ve kültürüyle irtibatlı,yorumsama/yorumlama eksenine dayalı bir yöntem" [K.S., Psikiyatrist] olduğu düşüncesiyle hermönitik yaklaşımı benimsediğini söylemiştir. Transpersonel terapi yaklaşımını benimseyen bir katılımcı, bu yaklaşımın, özellikle terapiye gelen insanların "Niçin? ve Neden?" sorularına yanıt ararken onları ego ötesi/üstü bir düzeye yönlendirme noktasında önemli bir işlevi olduğunu söylemiştir. Ayrıca katılımcıların büyük çoğunluğu, aile terapisi hizmeti verirlerken aileyi bütünlük içerisinde bir sistem olarak ele alan sistemik aile terapisi yaklaşımını benimsediklerini söylemişlerdir.

Katılımcıların çoğunluğu, terapi hizmeti verirken eklektik bir yöntem anlayışı benimsediklerini belirtmişlerdir. Bu katılımcılar, yalnızca bir kurama ya da tekniğe bağlı bağlı kalmak yerine, duruma, gelen danışanların ihtiyaçlarına ve terapinin seyrine göre terapi sürecinde birden fazla yöntemi kullandıklarını ifade etmişlerdir. Soru formlarında da uzmanların kuramsal olarak psikanaltik kuram ve bilişsel davranışçı yaklaşımları benimsedikleri, uygulamalarda ise çoğunlukla eklektik bir yöntem tercih ettikleri yönünde bilgiler elde edilmiştir.

Bununla birlikte, özellikle çocuklarla çalışırken gelen problemleri değerlendirme ve tanı koyma aşamasında dinamik yaklaşımı tercih ettiklerini belirten terapistler olmuştur. Dinamik yaklaşım sayesinde mevcut problemlere daha bütüncül bakabilme imkânı sağladıklarını belirten bazı katılımcılar, problemlere çok yönlü ve daha bütüncül bakmayı sağlayabilecek başka bir yöntemin eksikliği nedeniyle de dinamik yaklaşımları tercih etmek zorunda kaldıklarını belirtmişlerdir. Ancak, dinamik yaklaşım benimsenerek uygulanacak bir tedavinin çok uzun sürmesi ve dinamik yaklaşımın vakaları değerlendirirken esneklikten uzak, kesin bir çerçeve içinde hareket etme zorunluluğu getirmesi nedeniyle katılımcılar, uygulamalarda bu yaklaşımı pek tercih etmediklerini belirtmişlerdir.

Katılımcılara, benimsemiş oldukları kuram ve tekniklerin kendilerine gelen problemleri değerlendirmede, bu problemlere çözüm üretmede eksik kalan yönlerinin olup 
olmadığı, eğer varsa bu eksikliklerin nedenlerinin neler olabileceğine dair sorular da yöneltilmiştir. Katılımcıların büyük çoğunluğu, mevcut kuram ve tekniklerin eksikliklerinin olabileceği noktasında hemfikirdirler. Bazı katılımcılar, bu durumu "hiçbir kuramın insana dair hakikati tam manasıyla kavrayamayışına" [K.S., Psikiyatrist] bağlarken bir kısmı ise özellikle bazı terapi alanlarındaki kuramsal/teorik çalışmaların azlığına dayandırmışlardır. Bunun yanı sıra mevcut kuramların kültürel olarak bu kültüre uymadıklarından dolayı eksikliklerinin olduğunu ifade eden katılımcılar olmuştur. Buna mukabil, iki katılımcı mevcut "kuramsal bilgiler Batı'da üretiliyor olsalar da orada da insana yönelik üretildikleri için" [H.A.G., P. Danışman] bu bilgilerin kültüre uyumlu olup olmama gibi bir sorun teşkil etmeyeceklerini belirtmişlerdir. Dolayısıyla katılımcıların çoğu, asıl eksikliğin kuram ve tekniklerden değil, bu kuram ve teknikleri uygulayan terapistlerden kaynaklandığını, onların içinde bulundukları kültüre, danışanlarının kültürel özelliklerine duyarlı olmayışlarından kaynaklandığını belirtmişlerdir.

"Terapi tekniği değil de o içinde bulunduğunuz kültürün gerçeklerini yadsıyarak ve yok sayaraktan çalışıp çalışmamanız önemli. Terapi tekniklerinin hiç birisinde o şeyleri yok saydığını sanmıyorum. yok sayan, orda o işi uygulayan terapistin kendisi, dünya görüşü, hayatı algılayışı" [H.A.G., P. Danışman]

“...yani insanlar tamam kültürel olarak getirdiği inanç, kültür falan biraz fark ediyor; ama o kadar da farklı değiller. yani insan dediğimiz şey aşağı yukarı aşırı derecede farklı olan insanlar değil. Ama zaten iyi bir terapist, hiç önemli değil hastanın kültürel şeyini hep göz önünde bulundurur." [F.Y., Psikiyatrist]

Bu değerlendirmelerinin akabinde katılımcılara, bu kuram ve tekniklerdeki eksikliklerin bertaraf edilmesi için neler yapılması gerektiği ve kendilerinin bu anlamda kişisel ya da kurumsal çalışmalarının olup olmadığı sorulmuştur. Katılımcıların büyük çoğunluğu, terapide önemli olanın benimsenen kuram ve teknikten ziyade terapistin içinde bulunduğu toplumun, insanların gerçeklerini, kültürel özelliklerini, geleneklerini ve ananelerini iyi bilmek olduğunu vurgulamışlardır. Çünkü terapide asıl olanın "kullanılan teknikten ziyade, danışanla kurulan güven ilişkisi" olduğu ve bu güven ilişkisi kurulmadığında tekniğin de "havada kalması"nın söz konusu olduğu vurgulanmıştır.

Bazı katılımcılar, kuram ve tekniklerin eksik kalan yönlerinin eklektik bir yaklaşım benimsenip giderilebileceğini söylemişlerdir. Bu şekilde bir yöntemin eksikliği diğeri ile giderilerek danışanın sorunlarına kısa sürede çözüm üretmenin mümkün olduğu belirtilmiştir. Bununla birlikte kuramlardaki eksikliği gidermek için kuramları destekleyecek ya da eksikliklerini ortaya koyacak bilimsel çalışmaların sayısının artmasının gerekliliğini vurgulayan katılımcılar olmuştur. Türkiye'de bilimsel çalışmanın yeterli düzeyde olmadığını, hatta bilime gereken önemin verilmediğini söyleyen bu katıIımcılara göre, mevcut kuramları eleştirel bir şekilde ele alıp alternatif yaklaşımlar geliştirmek için de bilimsel çalışma yapmak gerekmektedir. Dolayısıyla kuramların da değişebileceğini göz önünde bulundurup "hiçbir kuramın muhafazakârı olmadan" [F.Y., 
psikiyatrist] bilimsel çalışmalar yaparak yeni bir şeyler ortaya konulabileceği ve kuramların eksikliklerinin bu şekilde ortadan kaldırılabileceği savunulmuştur.

Görüşme yapılan katılımcıların büyük çoğunluğu, terapi kuramlarında ve tekniklerinde tespit ettikleri bu eksiklikleri gidermek için bireysel olarak danışanlarının ihtiyaçlarına, kültürel özelliklerine öncelik vermeye ve bu kültürün örf ve adetlerine mümkün olduğunca hâkim olmaya çalıştıklarını belirtmişlerdir. Bu amaçla terapi seanslarında kültürel öğeleri, hikâyeleri kullandıklarını belirten katılımcılar olmuştur. Kuramsal olarak kültürel bir yaklaşımın geliştirilmesi gerektiği vurgusunu yapan bazı katılımcılar ise bunu gerçekleştirmek için kişisel bazı gayretlerin ötesine geçemediklerini ifade etmişlerdir. Bir katılımcı, kültürel yaklaşımlar geliştirmek için, kişisel gayretlerin ötesinde kurumsal çalışmaların da kurumsal çalışmaların da gerçekleştirilemediğini belirtmiştir. Bu durumu da "Türkiye'de kurumların kalıcı bir çaba ortaya koyamayıp siyasetin gölgesinde kalması ve dolasıyla bazı şeylerin kökleşememesine" [K.S., Psikiyatrist] bağlamıştır. Başka bir katılımcı ise kültürel yaklaşımların geliştirilmesi noktasındaki tespitlerini bireysel veya kurumsal çalışmalarla destekleyip desteklemediği sorulduğunda, "bu noktada ciddi ızdırap duyduğunu"; ancak, bir çalışma gerçekleştirilemediğini belirtmiştir. Kurumsal olarak kültüre özgü çalışmaların, araştırmaların yürütüleceği, eğitimlerin verileceği, psikoloji mezunlarının yönlendirilip eğitilebileceği bir araştırma merkezi kurma düşünceleri olsa da maddi kaynak yetersizliğinden dolayı bu projenin gerçekleşemediğini belirtmiştir.

\section{Uzmanların, Sıklıkla Karşılaştıkları Aile Problemlerine ve Aile Yapısındaki Değişimlere Bakışları}

Yarı yapılandırılmış görüşmelerde terapi hizmeti veren uzmanlara, ailelerin ne tür problemlerle kendilerine başvurdukları sorulmuştur. Buradaki amaç, araştırmanın genel amacıyla bütünlük oluşturacağı düşüncesiyle, toplumda aile ve çocuk noktasında ne tür problemlerin olduğunu, uzmanların kendilerine gelen bu vakalar çerçevesinde toplumsal meseleleri ele alırken ve bu meselelere çözüm üretirken sahip oldukları referans noktaları arasında bir bütünlüğün/uyumun olup olmadığını tespit edebilmektir. Katılımcıların verdikleri cevaplar, Eşlerin beklenti ve bilgi düzeyinden kaynaklanan problemler, Aile içi iletişim problemleri olmak üzere 2 ana tema altında değerlendirilmiştir.

Katılımcıların bazıları, eşlerin çok yüksek beklentilerle evlendiklerini, bu beklentilerin karşılığını bulamayınca da problemlerin baş gösterdiğini belirtmişlerdir. Bazı katıIımcılar, özellikle son beş yılda, insanların çok yüksek beklentilerle, evliliğin her şeye çare olacağı, evlendiği an tamamıyla mutlu olunacağı gibi bir algıyla evlendiklerini belirtmişlerdir. Görüşme yapılan başka bir uzman da benzer problemlerden bahsetmiş ve evliliğe dair beklenti düzeyinin bu kadar yüksek olmasında, "televizyonda romantizm anlamında pompalanan" [M.D. Psikolog] eş ve aile imajının etkili olduğunu belirtmiştir. 
Katılımcılar tarafından vurgulanan bir diğer husus, eşlerin evlilik ile ilgili, özellikle de cinsellikle ilgili bilgisizce evlenmeleridir. Bunun sonucunda da cinsel problemler başta olmak üzere birçok problemle terapistlere başvurmaktadırlar. Bir katılımcı, çeşitli konularda bilgisizce evlenme durumunun ortaya çıkardığı problemleri, evlilikle ilgili karşılaştıkları en temel problem olarak değerlendirmiştir.

Terapistlerin neredeyse tamamı, en fazla karşılaştıkları aile problemleri arasında eşlerin birbirleri ile, kendi ebeveynleri ve çocukları ile olan ilişkilerindeki iletişim problemlerini göstermişlerdir. Katılımcılar, evliliğin belli aşamalarındaki rollerin gereğini yerine getirememe, özellikle yeni evlilerde birbirini olduğu gibi, farklılıkları ile kabul etmekten ziyade kendine benzetmeye çalışma, aile içinde eşlerin birbirlerine yükledikleri anlamIarın sıradanlaşması ve değersizleşmesi, eşlerden birinin işinde başarı olup diğerinin bu tip imkânlardan yoksun oluşunun sebep olduğu problemleri ve özellikle hanımların ilgi, sevgi eksikliğinden dolayı yaşadıkları problemleri de sık karşılaştıkları aile problemleri arasında göstermişlerdir. Katılımcıların sıklıkla karşılaştıkları aile problemlerinden bir diğeri de eşlerden birisinin ailesiyle yaşanan problemdir.Üst ebeveyn müdahalesi olarak isimlendirdikleri bu durum, bazı katılımcılara göre bu topluma has bir özellik arz etmektedir:

"Yani eğer geleneksel aileyse, işte bu az önce söylediğim şey sıkıntısı olabiliyor, eşlerin anne babalarının evlilik içerisine müdahalesiyle ilgili sınır problemleri olabiliyor. işte malum bilinen gelin-kaynana şeyi gibi. bu, özellikle, ben ankara'da da çalışıım burda, bir buçuk yıldır burdayım, bu Ankara'daki toplumda daha fazla, iç anadolu'da özellikle, benim izlediğim şey...geleneksel ailede olan bir şey. o tür problemler oluyor, Türkiye'de hala var" [F.Y, Psikiyatrist]

Ebeveyn ve çocuklar arasındaki ilişkilerde ortaya çıkan problemlerin başında ise kuşak çatışması, çocuğa söz geçirememe, sınır koyamama, çocuğun kontrolünü sağlayamama gibi durumlar gösterilmektedir. Katılımcıların çoğu, kuşak çatışmasının oluşturduğu problemlere dikkat çekmişlerdir. Bazı katılımcılara göre, günümüzde kuşaklar arası fark neredeyse üç-dört seneye inmiş durumdadır. Böyle bir durumun ortaya çıkmasında ise özellikle medya ve popüler kültürün etkisi vurgulanmaktadır. Bununla bağlantılı olarak vurgulanan bir diğer husus da anne babanın otoritesinin giderek zayıflaması ve bu nedenle "çocuklarına söz geçirememe"leridir. Çocuk yetiştirme noktasında ailelerin "çocukları üzerinde kontrol sağlayamama, sınır koyamama vb" gibi problemlerin nedenleri sorgulandığında da karşımıza anne babaların çocuk yetiştirme sürecindeki tutumları çıkmaktadır:

"Bence aileler çocuklarıyla arkadaş olayım filan derken, ipin ucunu kaçırdıklarına arada hiçbir hiyerarşi gözetmedikleri simetrik ilişki kurdukları ve bunun sonucunda da böyle doyumsuz çocuklar, mutsuz çocuklar ve hani sınırını bilmeyen çocuklar yetiştirdiklerini düşünüyorum" [F.Y., P. Danışman] 
Başka bir katılımcı da aile içinde hem eşler arasındaki hem de ebeveynlerle çocukları arasındaki problemlerin oluşmasında internet faktörüne değinmiş ve genel anlamda kendisine bu türden vakaların geldiğini belirtmiştir:

"Yani internet, evdeki internet ve teknoloji ailelerin bence birçok yapısını bozdu. Yani mahremiyeti ortadan kaldırdığı için ailelerin o gizli anlaşmaları kendi içlerindeki dilleri bozulduğunu düşünüyorum ben. Bu hem çocuk için geçerli hem de çift için geçerli. Yani bir şekilde internetle beraberinde gelen ilişkilerin bozulması diyebilirim, genel anlamda gelen" [N.A., Psikolog]

Bununla birlikte neredeyse bütün katılımcılar, çocuk üzerinden gelen problemlerin çoğunun altında ailevi problemlerin yer aldığını vurgulamışlardır. Katılımcılar, bu tip problemlerde çocukların araç olarak kullanıldıklarını, bir anlamda "ailenin çocuk üzerinde semptom verdiğini, kendi arızasını çocuk üzerinde gösterdiğini" vurgulamışlardır.

Katılımcılar, ailelerin ergenlik dönemine ait problemlerle de yoğun bir şekilde karşılaştıklarını ve kendilerine başvurduklarını belirtmişlerdir. Ergenlerdeki beden algısı problemleri, uyum problemleri, cinsellikle ilgili problemler, katılımcıların bu döneme ait sıklıkla karşılaştıkları problemler arasındadır. Bununla birlikte bazı katılımcılar, aileler için ergenliğin kendisinin/çocuklarının ergenliğe girişinin bile ciddi bir problem kaynağı olarak görüldüğünü belirtmiştir. "Herhangi bir ekstra sıkıntısı olmayan,doktora geldiğinde herhangi bir patolojisi olmayacak, normal bir ergen bile" [F.Y., Psikiyatrist] geçiş döneminde ve birçok noktada değişim halinde olduğundan aile tarafından önemli bir problem kaynağı olarak algılanmaktadır. Bu durum - sonuç kısmında da tartışılacağı üzere-, kanaatimizce ergenliğe yüklenen anlamla doğrudan ilişkilidir.

Katılımcıların sıklıkla karşılaştıkları aile problemlerine dair bu yorumları, elektronik soru formlarından elde edilen sonuçlarla paralellik göstermektedir. Formlarda da çocuk yetiştirme sürecinde karşılaşılan problemler, eşler arasındaki iletişim problemleri, aile içi problemlerin çocuk üzerinden yansıtılması gibi durumlara işaret edilmiştir.

\section{Tartışma ve Sonuç}

Araştırmaya katılan terapi uzmanlarının, çoğunlukla hem teorik anlamda hem de uygulamalı anlamda, Türkiye'de psikoloji biliminin ve terapi hizmetlerinin mevcut durumuna dair eleştirel bir duruş benimsedikleri görülmüştür. Bu değerlendirmelerde kişisel ve kurumsal nitelik ve yetkinlik problemi, yasal düzenleme olmayışından dolayı alanın suistimale açık hale gelmesi, alanda kültüre özgü terapi yaklaşımlarının olmayışı gibi temalar ön plana çıkmıştır. Alandaki mevcut durum ile ilgili bu eleştirel düşüncelere mukabil, katılımcıların çoğunluğunun terapi hizmeti sunarken hem kuramsal hem de uygulamalı anlamda alandaki hâkim kuram ve yöntemleri tercih ettikleri görülmüştür. Bununla birlikte danışanların problemlerine "daha kısa sürede çözüm üretmek" için çoğunlukla eklektik bir yöntem anlayışının tercih edildiği görülmektedir. Bu yöntem anlayışı, her ne kadar problemi en kolay ve kısa sürede çözme noktasında oldukça 
işlevsel görülse de meseleye daha geniş bir perspektiften bakıldığında bu yöntemin kendi içinde önemli bazı problemleri barındırdığı söylenebilir. Zira Ratner'in (2011) de belirttiği gibi eklektisizm mevcut yaklaşımları tartışmaya açmayı ve onlara dair oluşacak eleştirelliği baskılamaktadır. Bununla birlikte eklektisizmin, terapistleri psikolojinin kültürel yönlerini anlamak için sahip olunması gereken prensip ve yönelimlerden de yoksun bıraktığını söyleyen Ratner (2003, s. 68), bu nedenle bu yöntemin kültüre dair sistematik yaklaşımların ortaya çıkmasını engellediğini belirtmektedir. Dolayısıyla bazı katılımcıların alandaki mevcut kuram ve terapi tekniklerinin eksikliklerini gidermek için de başvurdukları bu yöntemin, problemlere kısa vadede çözüm üretiyor görünse de hem kuramsal hem de uygulamalı olarak daha sistematik ve uzun vadeli çözümler üretmek açısından bir çıkış yolu olamayacağını söylemek mümkündür.

Araştırmaya katılan iki terapi uzmanının, alandaki hâkim terapi yaklaşımlarının dışında ve onlara alternatif olarak transpersonel psikoloji ve hermönitik terapi yaklaşımını benimsedikleri görülmüştür. Modern terapi yaklaşımlarının bireycilik vurgusuna mukabil, hermenötik terapide mensubu bulunulan kültürel ve tarihî bağlama aidiyeti vurgulanmakta ve psikoterapiste duygusal sorun ve mücadeleleri daha geniş bir toplumsal ve ahlaki bağlamda ele alma sorumluluğu yüklenmektedir (Sayar, 2011). Hermönitik terapinin ve terapistin mahiyetine dair bu açıklamalar, Fişek'in (1996) terapide bağlama duyarlılığın gerekliliğine yaptığı vurgu ile örtüşmektedir. Fişek'e (1996) göre, "Terapistin ekolü ne olursa olsun, danışanının içinde bulunduğu bağlama, o bağlamın etkilerine ve kendi bağlamı tarafından nasıl koşullandığına duyarlı olduğu sürece, daha etkin girişimlerde bulunabilecektir". Bu değerlendirmelerle görüşmeler esnasında, katılımcıların terapi yaklaşımlarındaki eksiklikleri gidermek için neler yapılması gerektiğine dair tespitleri birbirleriyle birebir örtüşmektedir. Katılımcıların çoğunluğu, benimsenen terapi ekolü ne olursa olsun, terapistin mensubu olduğu kültürün değer yargılarına, geleneklerine uzak olmaması, bu bağlamda danışanları ile iyi bir güven ilişkisi kurması gerektiğini vurgulamışlardır. Bu değerlendirmelerde, terapistlerin bağlam odaklılığı vurgulanmaktadır. Ancak, Arkonaç'ın (1999) ifadeleriyle bu defa da terapi modellerinin içinden neşet ettiği insan modelinin modernist bağlamı göz ardı edilmektedir. Yani terapide sadece terapistin bağlama duyarlıı̆ı̆ı yeterli görmek, kullanılmakta olunan terapi modellerinin içinden doğdukları varlık ve insan tasavvurunu, bilgi anlayışlarını göz ardı etmek demektir. Bu bakış açısı aynı zamanda terapi kuramları ile ilgili, meselelere farklı bir paradigmadan/anlam dünyasından/bilgi anlayışı içinden bakmanın da önünü kapamaktadır. Dolayısıyla burada yapılan iş sadece bireysel olarak bu kültüre duyarlı akademisyenlerin, terapistlerin Batılı bilgi anlayışını hem teorik hem de uygulamalı olarak buraya taşımalarıdır. Bu durum Tuna'nın (2011) Batılı bilgiye bağımlılık olarak olarak ifade ettiği teori ve düşünce ithalatının bir göstergesidir.

Her ne kadar meselenin paradigma düzeyinde ele alınması gerektiğini vurgulayan, bu kültürün anlam dünyasına dair yaklaşımların geliştirilip bilgi üretilmesi gerektiğini 
vurgulayan bazı katılımcılar olsa da bu tespitlerin bir temenniden öteye geçemediği, farklı bir dilin, yeni anlamların üretilemediğini söylenebilir. Bunun nedeni olarak hâkim bilgi anlayışının hem teorik/kuramsal hem de uygulamalı olarak kuşatıcı bir şekilde varlığını sürdürmesi ve kendini dayatması görülebilir. Bununla birlikte bu eksikliğin nedenlerini, bu kültüre/anlam dünyasına/düşünce geleneğine ait bilgilerin üretilmesi gerektiğini vurgulayan akademisyenlerin, bilim adamlarının, mensubu oldukları düşünce sisteminin/paradigmanın bilgi anlayışına, insan tasavvuruna vâkıf olup, bunu psikoloji bilimi içerisinde yeni bir dille üretecek yetkinliğe sahip olamayışlarında da aramak mümkündür. Zira, bir kişiyi veya onun mensubu olduğu kültürü anlayabilmek için o kültürün geçmiş/tarihî birikimine, bugününe, geleceğe yönelik beklentilerine dair bilgilerine bütüncül bir şekilde vâkıf olmak gerekmektedir (Kim ve Park 2006, s. 36). Ancak, Ratner'in (2003) da belirttiği gibi psikologlar/terapistler eğitimleri süresince-psikolojinin ideolojik olarak bireysel süreçlere yönelmesinden dolayı- mensubu bulundukları kültürün tarihî, felsefi geleneği ve sosyolojisi hakkında yeterli düzeyde bilgi sahibi olamadıkları için, her halükârda mensup olunan kültüre ait bilgi üretme noktasındaki çabalar da yetersiz kalmaktadır.

Katılımcıların aile problemleri çerçevesindeki değerlendirmelerinde ergenliğin kendisinin bile aileler tarafından bir problem kaynağı olarak algılandığına dair tespitleri oldukça manidardır. Çünkü ailelerin bu durumu, bu döneme dair üretilen bilgilerin toplumsal olarak ne tür yansımalarının olduğunu göstermesi açısından önemlidir. Zira önceki kısımlarda da belirtildiği gibi, ergenliğe dair literatür büyük oranda bu yaştaki insanları birçok noktada sorunlu, patolojiye yatkın olarak tarif etmektedir. Ergenliği tanımlamak için ortaya konulan bu özellikler, bugün toplumumuzdaki ergenlerin çoğunda gözlemlendiği ve bu durumun ergenliğe dair üretilen bilgileri desteklediği iddia edilebilir. Ancak üretilen bu bilgilerin, gençlerin doğal/fıtrî özellikleri olmaktan ziyade, hâkim Batılı psikoloji bilgisinin Batı dışı toplumlara aktarılması ile bireysel ve toplumsal olarak içselleştirilmesi neticesinde ortaya çıktığı söylenebilir. Zira ergenlik tarihsel kökenleri itibarıyla 19. yüzyılın sonlarında, Batı'da aile ve toplumdaki değişimler neticesinde ortaya çıkan toplumsal kategoriyi tarif etmek üzere kullanılmaya başlanan bir kavramdır (Demos \& Demos, 1969). G. Stanley Hall'ın 1904'te yayınladığı Adolescence kitabıyla da ilk defa bilimsel olarak ele alınmış ve insanın hayatının evrensel bir gelişim aşaması olarak görülmeye başlanmıştır (Steinberg ve Lerner, 2004, Arnett, 2006). Tarihsel olarak ortaya çıkışından günümüze kadar, insan hayatının doğal ve evrensel bir parçası olarak anlamlandırılan ergenliği, Lesko (2001) Batı kültürü tarafından inşa edilen, sosyal etkileşimleri görmezden gelip biyolojik özelliklere indirgenerek Batı dışı toplumlara aktarılan bir kavram ve anlama biçimi olarak değerlendirmektedir. Benzer şekilde Lüküslü (2009) de bu dönemi modernite tarafından üretilen bir sosyal kategori olarak telakki etmektedir. Dolayısıyla ergenliğe dair üretilen/inşa edilen ve özellikle medya, popüler kültür vb aygıtlar vasıtasıyla topluma aktarılan bu bilgiler, küresel olarak ortak bir "ergen kültürü"nün (Schlegel, 2000, s. 74) ortaya çıkmasına neden olmuştur. Dolayısıyla aileler, bu yaş grubundaki gençler ve toplumun diğer 
mensupları da kaçınılmaz olarak bu "kültürün"/anlam dünyasının içinde, ona uygun davranış örüntüleri sergilemektedirler.

Buna mukabil Robert Epstein, eğer bu yaş grubundaki gençler "ergen" olarak tanımlanmamış olsaydı, durumun şu an olduğundan daha farklı olabileceğini belirtmektedir (akt., Moshman, 2009). Bu tespitler, bu yaş grubuna dair farklı bir kavramsallaştırma ve anlam üretmenin gerekliliğini de ortaya koymaktadır. Ancak, yapılan görüşmelerde, ergenliğe dair mevcut bilgileri üreten psikoloji bilimi içerisinde mesleklerini icra eden terapistlerin çoğunun, uygulamalarının temelini oluşturan bu bilgi anlayışının mahiyetini sorgulamayışları oldukça manidar bir durumdur.

Katılımcıların, kendilerine gelen aile problemlerini ve bu problemlerin nedenlerini değerlendirirken bazı noktalarda daha geleneksel/kültürel referanslarla hareket ettikleri görülmektedir. Özellikle aile-çocuk ilişkilerindeki problemleri değerlendirirken, anne baba otoritesinin zayıflaması, çocuklar üzerinde kontrol sağlayamama, kuşaklar arası farkın çok hızıı bir şekilde artması, medyanın aile içi ilişkiler üzerinde menfi etkisi olduğu yönündeki tespitler, ortaya çıkan bu toplumsal değişimden memnun olunmadığını gösteren geleneksel/kültürel reflekslerdir. Ancak, burada dikkat çekici olan husus, katılımcıların kendilerine gelen ailevi problemleri, bunları ortaya çıkaran sebepleri değerlendirirken sahip oldukları bu muhafazakâr/geleneksel bakış açısının, bu problemlere çözüm üretirken, yerini alandaki hâkim Batılı kuram ve tekniklere bırakmasıdır. Bu durum, geleneksel referanslarla değerlendirilen problemlere çözüm üretirken, "Batılı bilgiye bağımlılığın" (Tuna, 2011) devam etiğini, bu bilgi anlayışının hâkimiyetini sürdürdüğünü göstermektedir.

Sonuç olarak psikolojide bu bağımlığı ortadan kaldırmak ve daha özgün bilgi üretebilmek için, meseleleri farklı bir paradigmanın/anlam dünyasının bilgi anlayışı/varlık tasavvuru çerçevesinde ele alan, daha sistematik ve bütüncül çalışmaların yapılması zaruri bir durum olarak karşımızda durmaktadır. 


\title{
Theory or Reality: Positioning and Searching in the Face of Dominant Theory and Practices of Therapy
}

\author{
Latif Karagöz*
}

The science of psychology produces objective, experiment-based, and universally accepted information within the modern scientific discourse. Thus, its practices in regards to humans and society are also within this framework. The paradigmatic crisis in the post 1960 period posed serious criticism against the main assumptions of psychology and made culture-central works and publications much more visible (Jahoda \& Krever, 1996; Kim, Yang \& Hwang, 2006). While schools of thought, including cross-cultural psychology, cultural psychology and indigenous psychology, strive to place culture in the centre of psychological studies, it seems that with a few important exceptions, the main school of Western psychological theory and applications continue to rule over psychology (Kağıtçıbaşı, 2010).

This situation largely applies to Turkish psychology. It can be said that the applications are similar whether one looks at the history of Turkish psychological writings or at the historical process of institutionalization. For example, according to Batur (2003), the acceptance of George Anschütz's arrival in Istanbul in 1915 as the starting point of the science of psychology in Turkey is a result of the dominant understanding in psychology because this approach reduces psychology to merely experimental psychology and ignores other ways of understanding in psychology.

Kuş (2007), in a study where he investigates the implications of paradigmatic transformation in social sciences to psychology, states that there are alternative approaches to the positivist paradigm in all disciplines of social sciences; however, psychology was influenced the least by this radical change. The accounts of psychologists participating in the study regarding the difficulty they faced in finding journals to publish their research results and academic support reinforces Kuş's evaluations.

According to Misra and Gergen (1993), psychology is primarily a product of EuropeanAmerican culture. However, this Western local psychology is transported to non-West-

* Res. Assist., Fatih Sultan Mehmet Vakıf University Department of Psychology. Correspondence: Ikaragoz@fsm.edu.tr, Fatih Sultan Mehmet Vakıf Üniversitesi Edebiyat Fakültesi, 34083, Fatih, İstanbul, Turkey. 
ern societies via the idea of being independent from values/culture which is presented as being a necessity of science and economic imperialism. In this sense, the science of psychology has an important function in conveying the Western conception of the human being, comprehension of knowledge, ways of understanding and thus the transformation of individuals and society in non-Western societies. This circumstance is interpreted by Arkonaç (2010) as the knowledge of subject/identity/agent and truth in Western epistemology carrying over to this region via its own elites, thus leading to the "colonization of the psyche."

Studies in developmental psychology are important as being one of the best fields reflecting this aspect of psychology because this field produces scientific information about life in a very wide spectrum ranging from pre-birth to childhood, school, marriage and business. It intervenes in the lives of human and society - theoretically and practically - with its Western, "universal" understanding of knowledge. Robinson (2001) notes that while there is an increase in the studies of psychologists dealing with culture-centered research, the current dominant knowledge of developmental psychology is produced by European-American psychologists in the wake of their own cultural experiences.

Studies and applications on adolescence are important to grasp this aspect of developmental psychology. When investigated, developmental psychology books, articles in this field and similar studies about adolescence almost always mention certain essential features, such as sadness, insecurity, pessimism, chaos through mind-body imbalance, guilt, shame and attraction toward opposite sex. Comments of some academicians, renowned for their work in developmental psychology, also consolidate these evaluations.

Parman (2008, p. 22) states that "no period of human life can be said to have contrasting and complex definitions such as this," while according to Kulaksızoğlu (2009, p. 52) "the development phase undergone together with girls and boys during childhood and puberty years is strictly peculiar to that period, depends on age and is a feature seen in all societies."

These identifications about adolescence in people aged roughly $12-22$ or 12-18 can be said to be very modern, secular and partly giving a definition of the adolescents which is almost always prone to psychopathology. Thus, the academic language used to describe a person this period, which can be said to include the most important stages in the formation of one's personality, also shows the conception of this type of understanding towards humans and adolescents.

Along with adolescence, attitudes in parenting also hold an important place in especially developmental psychology books as well as other publications. Nearly every developmental psychology book mentions five parenting attitudes; the democratic 
attitude, the authoritarian attitude, the permitting tolerant attitude, the permitting negligent attitude and the excessive simplistic attitude. Among these, the most befitting approach is considered to be the democratic attitude. According to Şendil \& Kaya Balkan (2005, p. 80), "families belonging to this approach are aware that their children are individuals, let their children realize themselves, grant them equal rights in the family, support openly expressing their thoughts, thus help them develop independent personalities."

When deeply dissected, this approach, which is presented as the ideal parenting attitude, can be said to define parents' relationship with their children in a slippery, even ambiguous, ground. Hence the privative influence on social practices of the family roles defined with equity, status given to parents in terms of friendship, fore grounded flexibility instead of parental discipline and the emphasis on a disconnected individual in the name of "realizing oneself" should be questioned. This is because an approach deemed to be "ideal" in this fashion, once again ignores the role culture plays on finding and analyzing the parent-child relationship. However, as Sümer (2005) states, parenting attitudes show differences according to culture and socioeconomic level. Therefore, this shows that it is necessary to form the theoretical knowledge within the framework of society's world of meaning and practices.

Beyond the theoretical knowledge produced in developmental psychology, it is important to observe what kind of reflection this knowledge has on practice. Thus a more sufficient and integrated evaluation about the science of psychology's current state in Turkey will be possible. The state of therapist practitioners equipped with this theoretical knowledge and practices in this field, since it is the best area to observe the influence of the science of psychology on practice, is an important indicator in this framework. Fişek (1996) says that there are too few acknowledgements in literature regarding how psychotherapies with theoretical and ideological rooted in Western Europe and North America are processed in other cultures.

In this sense, this study aims to determine how psychologists, counselors and psychiatrists evaluate the current state of the science of psychology and the psychotherapy services/practices. It also aims to make sense of the dominant Western theories and applications and consider whether they are in any pursuit of developing alternative approaches. A further aim of the study is to determine the references used while evaluating family problems, which is one of the most important social issues, and the change and transformation in the family. The purpose here is to investigate whether there is harmony between the methods of handling certain issues often faced by therapists and the accepted theories and methods while also attempting to find solutions to these issues. 
Interviewing, as one of the qualitative techniques, is used in this research. An indepth interviewing technique "allows open ended questions to be asked, listened, their answers recorded and the research topic to be examined in detail with related additional questions" (Kümbetoğlu, 2008, p. 71). In this respect, as Kümbetoğlu states (2008), an in-depth interviewing technique allows for transcending the visible side of social phenomena and reaching the essence of it, examining them in a deeper, more detailed and integrated fashion.

Interviews were made with 10 psychotherapy experts, in particular those who work with families, children or adolescents, practicing in Istanbul. Three of these experts work as psychiatrists, four as psychologists, and four as counselors. The interviewees were chosen through the use of "snowball sampling," which is often used in qualitative research. By this way, other interviewees were reached via source persons. In the snowball sampling, there is a risk in reaching only specific groups and persons (Kümbetoğlu, 2008, p. 99). It was attempted to avoid this risk by determining two source persons. In addition to snowball sampling, considering that excessive or contradictory situations can provide a richer data as compared to normal situations and thus the research problem would be understood in depth and in multi-layered fashion (Yıldııım \& Şimşek, 2000) excessive or contradictory situation sampling was also used. Interviews were conducted by making appointments beforehand and going to the institutions at the specified date and time. Interviews were recorded and these recordings were transcribed. These texts were read several times and analyzed with "systematic analysis," one of the qualitative data analysis methods. In systematic analysis, "in addition to the descriptive presentation of data in order to reach some causal and explanatory conclusions, after determining some of the concepts and themes in the data, it is essential to identify the relationship between them" (Kümbetoğlu, 2008, p. 154). Using the data gathered in this research, specific common themes were composed and the participants' answers were classified under these themes. Data gathered by a total of 13 electronic questionnaires were also classified under specific categories. Afterwards, both the data gathered from interviews and electronic questionnaires were analyzed in an integrated manner.

Therapy experts who participated in the research were mostly observed to take a critical stand, both in theoretical and practical sense, against the current state of science of psychology and therapy services in Turkey. The foregrounding themes in these evaluations were personal and institutional quality and proficiency problems, the field being vulnerable to misuse due to the non-existence of a legal regulation and the absence of culture oriented therapy approaches in the field. Contrary to these critical thoughts on the current state of the field, it has been seen that the majority of participants preferred the dominant theories and methods in both theoretical and institutional sense while giving therapy service. It has also been observed that, in order 
to "solve the problems of the client in a shorter period," mostly an eclectic understanding of methods has been preferred. While this understanding seems to be functional in solving problems in a short period and in the easiest way, from a wider perspective it can be said that this method includes a number of problems. As Ratner (2011) points out, eclecticism represses debates about existing approaches and criticism against them. Moreover, Ratner (2003, p. 68) states that eclecticism denies therapists from principles and tendencies necessary to understand the cultural aspects of psychology thus preventing the emergence of systematic approaches about culture. Therefore, it is apparent that while this method, which some of the participants use to alleviate the deficiencies of available theories and therapy techniques, seems to be producing solutions in a short period, it cannot produce more systematic and longer term solution, both theoretically and practically.

Two therapy experts who participated in the research were seen to be adopting a transpersonal psychology and a hermeneutic therapy approach, which are outside the dominant therapy approaches and considered as alternatives. Contrary to the modern therapy approaches' emphasis on individualism, in hermeneutic therapy cultural and historical belonging is emphasized and the responsibility to take emotional problems and struggles in a wider social and moral context are imposed on the psychotherapist (Sayar, 2011). These accounts on the disposition of hermeneutic therapy and the therapist correspond to Fişek's (1996) emphasis on the necessity of sensitivity on context. According to Fişek (1996), "whatever the therapist's school might be, as long as $\mathrm{s} / \mathrm{he}$ is sensitive to the context the client is in, to the influences of that context, and to how conditioned s/he is by his own context, s/he can make more efficient attempts." These evaluations correspond to the participants' identifications pertaining to what must be done to remove deficiencies in therapy approaches. The majority of the participants stated that whatever the therapist's school might be, the important thing is not to drift away from his/her own culture's values and traditions; and in this context, s/he should construct a positive, trusting relationship with his client. In these evaluations, therapists' focus on context is emphasized. However, as Arkonaç (1999) notes, this time the modernist context of human model which stems from therapy models is ignored. In other words, regarding a therapist's mere sensitivity to context as being sufficient in and of itself is equivalent to ignoring the conception of entity and human, an understanding of knowledge which arises from the current therapy models being used. This point of view also prevents the perspective regarding issues related to therapy theories from a different paradigm/world of meaning/understanding of knowledge. Thus what happens here is that these academicians and therapists who are sensitive to culture merely on an individual level, carry over the Western understanding of knowledge both theoretically and practically. This situation is an indication of the theory and thought importation which Tuna (2011) explains as an addiction to Western knowledge. 
Even though there are some participants who emphasize that the issue should be considered in relation to the paradigm, and approaches related to the culture here should be developed to produce knowledge, it can be said that these evaluations go no further than being sentiments, and that a different language or new meanings are not produced. The reason for this is that the dominant understanding of knowledge continues to exist in a surrounding fashion both theoretically and practically, and continues to impose itself. Nevertheless, it is possible to search the reasons for these deficiencies in whether the academicians and scientists who emphasize the production of knowledge belonging to culture/world of meaning/tradition of thought are cognizant of this paradigm's/thought system's conception on humans and the way of understanding; and whether they have the proficiency to produce this with a new language in the science of psychology. Because to understand a person and the culture that that person belongs to, it is necessary to be cognizant, in a holistic fashion, of that culture's history and have knowledge about its present and future expectations (Kim \& Park, 2006, p. 36). However, as Ratner (2003) states, since psychologists/therapists during their education do not gather enough knowledge about the history, philosophical tradition and sociology of the culture they belong to - because of psychology ideologically leaning towards individualism - efforts to produce knowledge about culture continue to fall short.

Participants' considerations about adolescence, in their evaluations in the frame of family problems, being seen as a problem by families themselves are quite significant. Because one's family situation is important in terms of showcasing the influences of the knowledge produced about this period. As mentioned before, literature about puberty describes people in this age mostly as troubled and prone to pathology. It can be claimed that these features are observed in adolescents today in Turkish society, and that this supports the knowledge produced about adolescence. However, rather than this knowledge being natural features of young individuals, it can be said to have emerged as a result of the dominant Western knowledge of psychology being transferred to non-Western societies and internalized socially. Because adolescence is a notion used to describe the social category emerged from the changes in family and society in the West towards the end of 19th century (Demos \& Demos, 1969). It was first considered scientifically in G. Stanley Hall's book, Adolescence, published in 1914, and started to be seen as a universal developmental phase of human life (Arnett, 2006; Steinberg \& Lerner, 2004).

Lesko (2001) considers adolescence, which was historically deemed as a natural and universal part of human life since the day it emerged, to be a notion and a way of understanding constructed by Western culture, which ignores social interaction and is reduced to biological features. Similarly, Lüküslü (2009) also considers this period as a social category produced by modernity. Hence this produced/constructed knowledge about puberty and transferred especially via media, popular culture and similar 
devices cause the emergence of a globally common "adolescence culture" (Schlegel, 2000, p. 74). Hence families, youth falling in this age group and other members of society who are in this culture/way of understanding, inevitably display behaviors convenient to it.

In contrary, Robert Epstein states that if people in this age group were not identified as "adolescents," then the situation could have been different (as cited in Moshman, 2009). These findings, in a sense, put forward the necessity of a different conceptualization and meaning production about this age group. However, it is significant that most of the therapists have not questioned the quality of this world of knowledge.

It is seen that participants, while evaluating family problems and the reasons for them, at some points act on a more traditional/cultural reference. Considerations such as weakened parental discipline, the inability to maintain control over children, the difference between generations rapidly increasing, media having a negative effect on the family, especially while evaluating the problems in family-child relationships, are traditional/cultural reflexes indicating dissatisfaction over this social change. However, a noteworthy point here is that the conservative/traditional point of view that participants have while evaluating the family problems and their reasons, is dropped in the sake of Western theory and techniques while trying to find solutions to them. This situation shows the "dependence on Western knowledge" (Tuna, 2011) in the holistic handling of problems and finding solutions is ongoing. In order to remove this dependence on psychology and produce a more authentic knowledge base, it stands before us as an obligatory situation to do more systematic and holistic research which handles issues in the frame of an understanding of knowledge/entity conception belonging to a different paradigm/world of meaning.

\section{References / Kaynakça}

Arkonaç, S. A. (1999, Eylül). Türkiye'deki terapist söyleminde insan, kültür ve terapi. Uluslararası Liyezon Psikiyatrisi Kongresi'nde sunulan bildiri, İstanbul.

Arkonaç, S. A. (2004). Doğunun ve batının yerelliği: Bireylik bilgisine dair. İstanbul: Alfa Yayınları.

Arnett, J. J. (2006). G. Stanley Hall's adolescence: Brilliance and Nonsense, History of Psychology, 9 (3), 186-197.

Batur, S. (2003). Türkiye'de psikoloji tarihi yazımı üzerine. Toplum ve Bilim, 98, 255-264.

Demos, J., \& Demos, V. (1969). Adoloscence in historical perspective. Journal of Marriage and Family, 31 (4), 632-638.

Fişek,G. (1996). Psikoterapide Bağlamsal Duyarlılık ve Batı Kökenli Psikoterapilerin Uygulanması. http:// www.bupampsi.boun.edu.tr/?q=node/63 adresinde 12 Nisan 2012 tarihinde edinilmiştir.

Jahoda, G., \& Krewer, B. (1997). History of cross-cultural and cultural psychology. J. W. Berry, Y. H. Poortiga, J. Pandey (Eds.), Handook of cross-cultural psychology (2nd ed., vol. 1, pp. 1-42). Boston: Allynand Bacon. 
Kağıtçıbaşı, Ç. (2010). Benlik, aile ve insan gelişimi: Kültürel psikoloji. İstanbul: Koç Üniversitesi Yayınları.

Kim, U., Yang, K. S., \& Hwang, K. K. (2006). Contributions to indigenous and cultural psychology: Understanding people in context. In U. Kim, K. S. Yangand, \& K. K. Hwang (Eds.), Indigenous and cultural psychology: Understanding people in context (pp. 3-27). New York: Springer.

Kim, U., \& Park, Y. S. (2006). The scientific foundation of Indigenous and cultural psychology: The transactional approach. In U. Kim, K. S. Yangand, \& K. K. Hwang (Eds.), Indigenous and cultural psychology: Understanding people in context (pp. 27-49). N.Y: Springer.

Kulaksızoğlu, A. (2009). Ergenlik psikolojisi. İstanbul: Remzi Kitabevi.

Kuş, E. (2007). Sosyal bilim metodolojisinde paradigma dönüşümü ve psikolojide nitel araştırma. Türk Psikoloji Yazıları, 10 (20), 19-41.

Kümbetoğlu, B. (2005). Sosyolojide ve antropolojide niteliksel yöntem ve araştırma. İstanbul: Bağlam Yayınları.

Lesko, N. (2001). Act your age!: A cultural construction of adolescence. New York: Routledge.

Lüküslü, D. (2009). Türkiye'de gençlik miti: 1980 sonrası Türk gençliği. İstanbul: İletişim Yayınları.

Misra, G., \& Gergen, K. J. (1993). On the place of culture in psychological science. International Journal of Psychology, 28 (2), 225-243.

Moshman, D. (2009). A world without adolescence (Book Review). Journal of Applied Developmental Psychology, 30 (3), 378-380.

Parman, T. (2008). Ergenlik ya da merhaba hüzün. İstanbul: Bağlam Yayınları.

Ratner, C. (2003). Theoretical and methodological problems in cross-cultural psychology. Journal of the Theory of Social Behavior, 33, 67-94.

Ratner, C. (2011). Cultural psychology. http://www.sonic.net/ cr2/springer\%20chap.pdf adresinden 20.03.2012 tarihinde edinilmiştir.

Robinson, L. (2001). A conceptual framework for social work practice with black children and adolescents in the United Kingdom: Some first steps. Journal of Social Work, 1, 165-185.

Sayar, K. (2011). Terapi: Kültürel bir eleştiri. İstanbul: Timaş Yayınları.

Schelegel, A. (2000). The global spread of adolescence culture. In L. J. Crockett, R. K. Silbereisen (Eds.), Negotiating adolescence in times of social change (pp. 71-89). Cambridge: Cambridege Universty Press.

Sümer, N. (2005). Anne-baba tutum ve davranışlarının çocuğun duygusal gelişimi üzerindeki etkileri. http:// www.metu.edu.tr/ nsumer/indexdosyalar/bap 2005tr.pdf adresinden 15 Aralık 2011 tarihinde edinilmiştir.

Steinberg, L., \& Lerner, R. M. (2004). The scientific study of adolescence: A brief history. The Journal of Early Adolescence, 24 (45), 45-54.

Şendil G. ve Kaya Balkan, İ. (2005). Anne baba olmak. İstanbul: Morpa Kültür Yayınları.

Tuna, K. (2011). Batılı bilginin eleştirisi. İstanbul: İz Yayıncılık.

Yıldırım, A. ve Şimşek, H. (2000). Sosyal bilimlerde nitel araştırma yöntemleri. Ankara: Seçkin Yayıncılık. 
